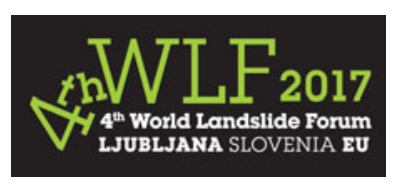

\title{
International Council for Science (ICSU) - On the Future Challenges for the Integration of Science into International Policy Development for Landslide Disaster Risk Reduction
}

\author{
Irasema Alcántara-Ayala, Virginia Murray, Philip Daniels, \\ and Gordon McBean
}

\begin{abstract}
In 2015 four UN landmark agreements were developed: the Sendai Framework for Disaster Risk Reduction 2015-2030 (hereafter referred to as the Sendai Framework); the agenda related to Financing for Development; the Sustainable Development Goals and the Paris Agreement on Climate Change. These can be regarded as the main guiding documents to galvanise action to address the new or emerging global challenges. The Science and Technology community are asked to support the implementation of the Sendai Framework, in order to 'prevent new and reduce existing disaster risk' by 'enhancing the scientific and technical work on disaster risk reduction and its mobilization through the coordination of existing networks and scientific research institutions at all levels and all regions with the support of the UNISDR Scientific and Technical Advisory Group (STAG)' (UNISDR in Sendai Framework for Disaster Risk Reduction 2015-2030, 2015a, Paragraph 25g). Within the Sendai Framework agenda, the commitment of STAG and the Integrated Research on Disaster Risk Program (IRDR) is focusing the integration and collaboration between science, policy and practice. IRDR is a multi-disciplinary, all-hazards approach, supported by the International Council for Science (ICSU), the International Social Science Council (ISSC) and the United Nations Office for Disaster Risk Reduction (UNISDR), to strengthen capacity at global, regional and local levels to address hazards and generate science-based decisions on actions to reduce their impact (IRDR in Integrated research on disaster risk strategic plan 2013-2017, 2013). Along the line of critical actions identified by STAG and IRDR, particular efforts are being undertaken by the International Consortium on Landslides (ICL) to understand the configuration of landslide disaster risk and reduce its impacts. ICSU, via IRDR, as one of the voluntary signatories of the International Strategy
\end{abstract}

I. Alcántara-Ayala ( $\square)$

Institute of Geography, National Autonomous University of

Mexico (UNAM), Circuito Exterior, Ciudad Universitaria,

Coyoacán, 04510 Mexico City, Mexico

e-mail: irasema@igg.unam.mx

V. Murray · P. Daniels

Public Health England, London, SE1 8UG, UK

e-mail: Virginia.Murray@phe.gov.uk

P. Daniels

e-mail: Philip.Daniels@phe.gov.uk

G. McBean

Department of Geography, Social Science Centre Rm 2322,

The University of Western Ontario, London, ON N6A 5C2, Canada

e-mail: gmcbean@uwo.ca

G. McBean

International Council for Science, 75116 Paris, France 
for Disaster Reduction-International Consortium on Landslides (ISDR-ICL) Sendai Partnerships 2015-2025 for Global Promotion of understanding and reducing landslide disaster risk, is committed to enhance such endeavours. In this paper, attention is drawn to identifying some of the main future challenges for the integration of science into local, national, regional and international policy development for Landslide Disaster Risk Reduction within the Sendai Framework.

\section{Keywords}

Landslides $\bullet$ Science $\bullet$ Policy making • Practice $•$ Disaster risk reduction $\bullet$ Integrated research $\bullet$ Challenges

\section{Introduction - Landslides as a Major Hazard}

According to the World Bank, some 5\% of the total population on the earth, circa 300 million inhabitants live in an area of 3.7 million $\mathrm{km}^{2}$ susceptible to landslides (Dilley et al. 2005). It is considered that the impact of landslide disasters will continue to mount dramatically as a result of climate change (IPCC 2012, p. 15), population growth, and urbanization processes, leading to the establishment of regular and irregular human settlements on unstable slopes in both developed and developing countries.

Landslides are the concrete expression of slope instability, resulting from natural processes, human-induced factors and, quite commonly, the interactions of both. Deforestation processes, mining, excavations, loading of slopes, inappropriate terracing, artificial induced vibrations, deficient drainage and sewage systems are among the main anthropogenic determining factors of landslides (Alcántara-Ayala 2016).

A recent systematic review of landslides (Kennedy et al. 2015) showed that health impacts of landslides are poorly recorded. Estimates of mortality are frequently inaccurate (both over- and underestimated) and tend to emphasise the short-term impacts. Factors leading to high morbidity and mortality include the volume of material displaced, speed of displacement and vulnerability of the population.

Short-term physical health impacts include crushing, asphyxiation and inhalation of debris. Longer term physical health impacts include illness resulting from disruption and destruction of sanitation systems, as well as mental ill health and trauma resulting from direct involvement and/or from experience of loss and or trauma to loved ones. Economic losses can be significant, although are frequently greatest in high income countries, whereas injury and loss of life are lower than in developing countries due to improved mitigation, response and recovery.

Reasons for poor recording have been cited as:

- The location of many landslides in remote, often highly mountainous, areas in poor countries in which levels of reporting of lower impact events is likely to be variable;
- Misidentification of landslides, for example, a debris flow may be described as a flood, leading to them being incorrectly recorded;

- The co-occurrence of landslides with another (triggering) process, such as an earthquake, leading to the cause of death being incorrectly recorded;

- The difficulty of tracking down the occurrence of post-event mortality (Petley 2012)

Disaster risk is understood as the probability of loss of life, injury or damage/destruction of assets of a system, society or a community, determined by the interaction among hazard, vulnerability and exposure (ICSU-LAC 2010; UNISDR 2015b (see Fig. 1). While hazards can be of a natural, socio-natural or technological nature (Lavell 1996, 2003a; ICSU-LAC 2010; Oliver-Smith et al. 2016), vulnerability involves historically rooted economic, social, political, cultural and institutional multi-dimensions (Blaikie et al. 1994; Wisner et al. 2004; Oliver-Smith 2013; Oliver-Smith et al. 2016). Exposure refers to the physical location of individuals and societies, assets (including environmental), livelihoods and infrastructure in areas susceptible to hazards that are likely to be affected by potential losses or damage (UNISDR 2009, b).

Social processes shaped by the structure of development models and economic patterns of transformation have determined the social construct of disaster risk (Lavell 2003b).

The UN Landmark agreement in 2015, the Sendai Framework for Disaster Risk Reduction 2015-2030, was adopted by 187 countries in March 2015 and endorsed by the UN General Assembly in June 2015. It states that there is a need for focused action within and across sectors by states at local, national, regional and global levels in the four priority areas, with the understanding of risk being the first priority. For landslides, understanding risk therefore requires a full comprehension of causality, in other words, identifying, and assessing root causes of disaster risk, in addition to dynamic pressures or drivers of risk in order to be properly addressed (Burton 2010, 2015). 


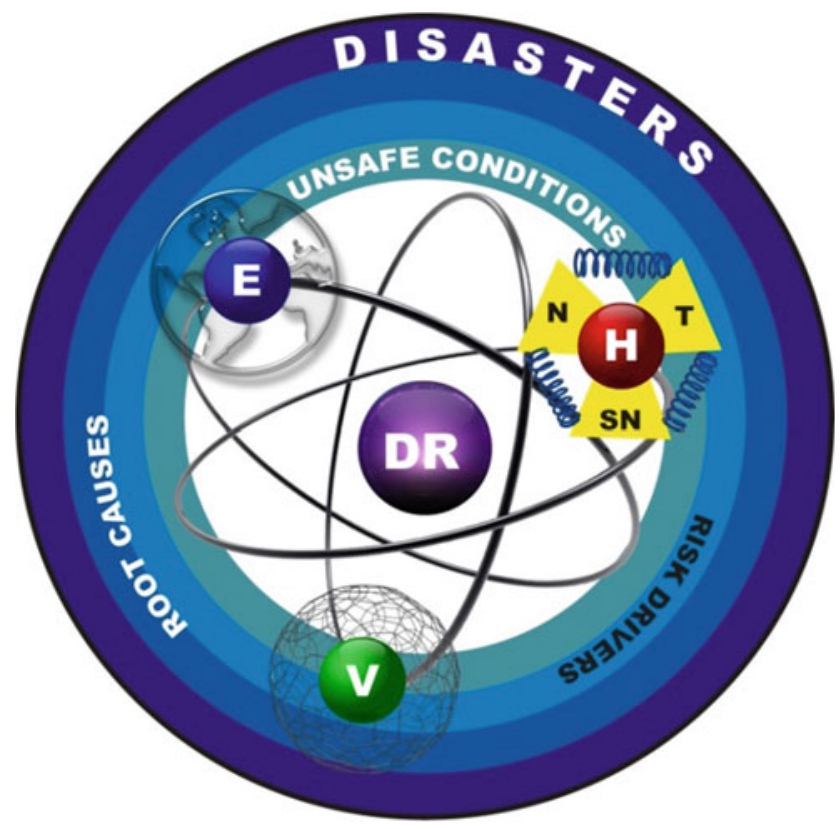

Fig. 1 The key relationships and processes in the social construction of risk ( $E$ exposure; $V$ vulnerability; $H$ hazard, $N$ natural, $T$ technological and $S N$ socio-natural; $D R$ disaster risk). Source Oliver-Smith et al. (2016)

Degradation of the environment, land-use changes, urbanization, migration, climate change and deficient governance are among drivers associated with exposure and vulnerability increasing risk, as they amplify unsafe conditions that potentially lead to landslides. These patterns of risk influence the creation of new risks, including landslides, at global, regional, national and local scales (Oliver-Smith et al. 2016) (Fig. 1).

When destabilized by physical characteristics and processes, coupled with the potential to affect societies, slopes can be transformed into hazards. Likewise, when human intervention on the environment takes place in areas susceptible to landslides, enhancing their occurrence and potential impact on societies, they are considered as socio-natural hazards. Excluding large mass movement processes resulting from volcanic or seismic activity and/or tsunami, most rainfall triggered landslides that are transformed into disasters are of socio-natural type (Alcántara-Ayala 2016).

\section{Global Frameworks to Reduce Disaster-Risks, Hazards and Vulnerability}

Reflecting the complex causality of disasters outlined above and following several decades of international negotiations, strategies and initiatives aimed at preventing and lessening the impact of disasters, 2015 became a watershed year for

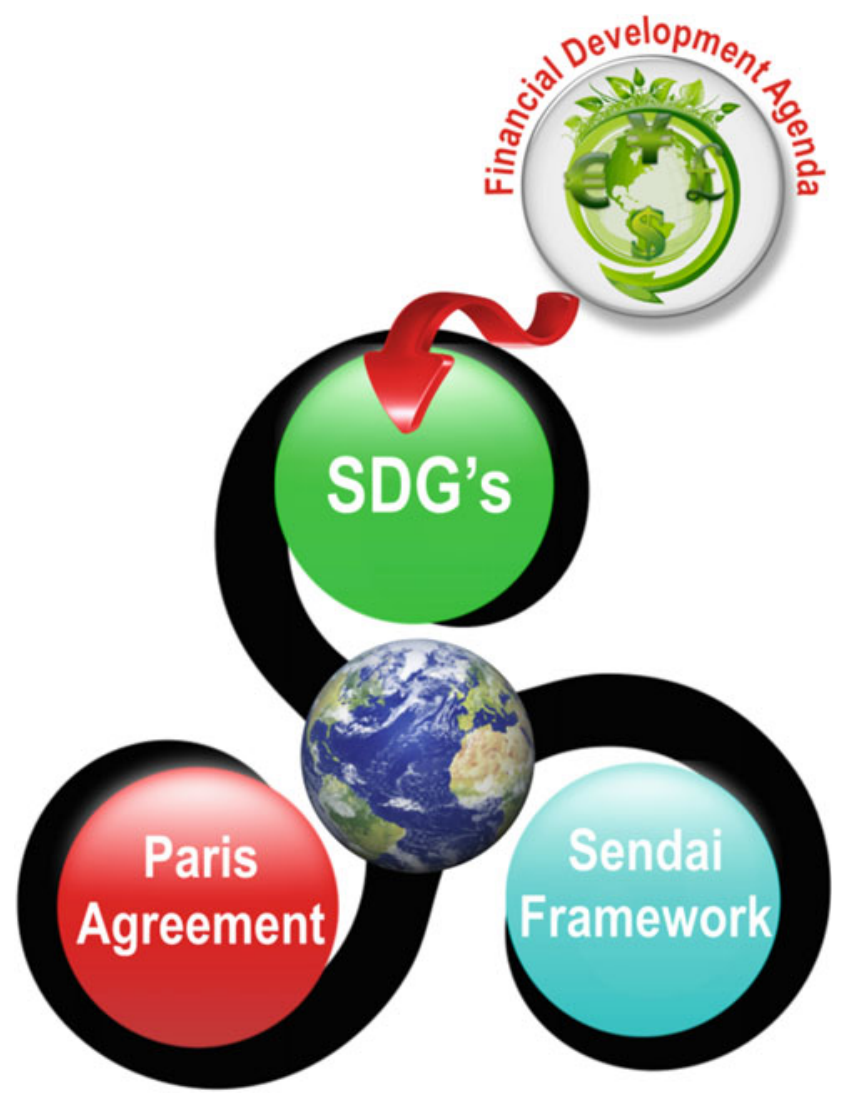

Fig. 2 Intertwined convergence of the key four 2015 landmarks to achieve DRR and DRM. SDGs are sustainable development goals

disaster risk reduction, science and policy making, with four United Nations landmark international agreements being agreed (Fig. 2). These four agreements are listed below:

- Third United Nations World Conference on Disaster Risk Reduction in Sendai, Japan (Sendai Framework for Disaster Risk Reduction 2015-2030

- Third United Nations International Conference on Financing for Development in Addis Ababa, Ethiopia

- United Nations Sustainable Development Goals in New York, USA (SDG's); and

- The United Nations Framework Convention on Climate Change in Paris, France

\section{The Sendai Framework for Disaster Risk Reduction 2015-2030}

Derived from its predecessor Hyogo Framework for Action 2005-2015 (HFA), the Sendai Framework for Disaster Risk Reduction consists of seven targets, four priorities for action and thirteen guiding principles which are summarised in Fig. 3. 
Fig. 3 A diagrammatic interpretation of the structure of the Sendai framework for disaster risk reduction (2015-2030) reflecting its seven global targets, its four priorities for action and its thirteen guiding principles. Source adapted from UNISDR (2015a)

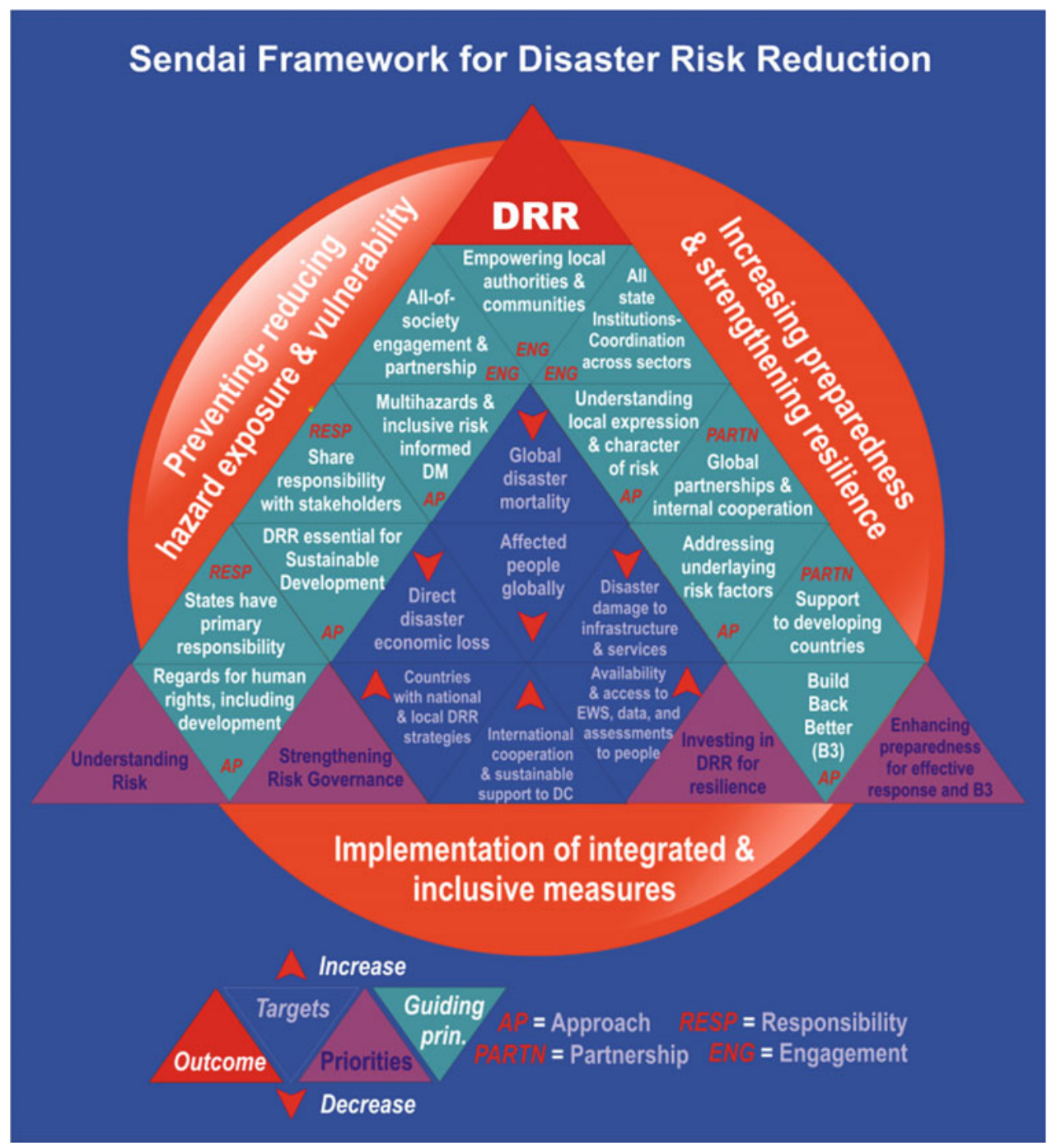

Its scope and purpose is directed towards guiding 'the multi-hazard management of disaster risk in development at all levels as well as within and across all sectors' by taking into account 'the risk of small-scale and large-scale, frequent and infrequent, sudden and slow-onset disasters, caused by natural or manmade hazards as well as related environmental, technological and biological hazards and risks' (UNISDR 2015a, Paragraph 15).

The Sendai Framework aims to achieve 'the substantial reduction of disaster risk and losses in lives, livelihoods and health and in the economic, physical, social, cultural and environmental assets of persons, businesses, communities and countries' (UNISDR 2015a, Paragraph 16). To achieve this outcome, the following goal must be pursued 'Prevent new and reduce existing disaster risk through the implementation of integrated and inclusive economic, structural, legal, social, health, cultural, educational, environmental, technological, political and institutional measures that prevent and reduce hazard exposure and vulnerability to disaster, increase preparedness for response and recovery, and thus strengthen resilience' (UNISDR 2015a, Paragraph 17).

\section{Third United Nations International Conference on Financing for Development}

This agreement, confirmed in Addis Ababa in July 2015 contains three main tasks (AAAA 2015):

- to follow-up on commitments and assess the progress made in the implementation of the Monterrey Consensus and the Doha Declaration;

- to further strengthen the framework to finance sustainable development and the means of implementation for the universal post-2015 development agenda; and

- to reinvigorate and strengthen the financing for development follow-up process to ensure that the actions to 
which we commit are implemented and reviewed in an appropriate, inclusive, timely and transparent manner.

The agreement aims to end poverty and hunger, protect the environment, and promote inclusive economic growth and social inclusion (Paragraph 1). The Agenda also recognizes the importance of aligning climate, humanitarian and development finance (Paragraphs 62-66), as well as developing data, disaggregated by age, sex and socioeconomic group, in order to support research and programming (Paragraph 126) (AAAA 2015).

Crucially, in the context of this paper, the agenda pledged that, by 2020, the United Nations (AAAA 2015):

- "will increase the number of cities and human settlements adopting and implementing integrated policies and plans towards inclusion, resource efficiency, mitigation and adaptation to climate change and resilience to disasters. We will develop and implement holistic disaster risk management at all levels in line with the Sendai Framework. In this regard, we will support national and local capacity for prevention, adaptation and mitigation of external shocks and risk management", (34);

- "Encourage consideration of climate and disaster resilience in development financing to ensure the sustainability of development results" (64);

- "Enable countries to prevent or combat situations of chronic crisis related to conflicts or natural disasters ... [recognising] the need for the coherence of developmental and humanitarian finance to ensure more timely, comprehensive, appropriate and cost-effective approaches to the management and mitigation of natural disasters and complex emergencies. We commit to promoting innovative financing mechanisms to allow countries to better prevent and manage risks and develop mitigation plans. We will invest in efforts to strengthen the capacity of national and local actors to manage and finance disaster risk reduction and to enable countries to draw efficiently and effectively on international assistance when needed" (66).

The agreement further encouraged consideration of further debt relief steps, where appropriate, and/or other measures for countries affected by disasters.

\section{The 2030 Agenda for Sustainable Development- the Sustainable Development Goals}

Unlike the Millennium Goals, their successors, the Sustainable Development Goals (SDGs), known officially as the 2030 Agenda for Sustainable Development, are characterized by being 'Universal', that is to say, they should be applicable to all countries. They are also intended to be an integrated and transformative vision for a better world, as a function of five-sided baselines: People, Planet, Prosperity, Peace and Partnership. The SDGs aim at ending poverty and hunger; protecting the planet from degradation; ensuring that all human beings can enjoy prosperous and fulfilling lives at the same time that development is in equilibrium with nature; fostering peaceful, just and inclusive societies; and enhancing Global Partnerships for the Implementation of the Sustainable Development Agenda (United Nations 2015).

The urgent need to move towards disaster risk reduction (DRR) and management (DRM) is clearly embedded into the 2030 Agenda for Sustainable Development, which comprises 17 Sustainable Development Goals (SDGs) and 169 associated global targets.

Disaster risk reduction is a cross-cutting issue in different aspects and sectors of development and reflecting this, there are 25 targets, in 10 out of the 17 SDGs, that are strongly related to DRR (Table 1). They mainly address poverty, ending hunger, ensuring healthy lives, education, sustainable management of water, building resilient infrastructure, resilient cities, climate change and marine and terrestrial ecosystems goals.

\section{The 2015 Paris Agreement on Climate Change}

After more than two decades of intense negotiations, some commitments and fewer influential actions, the 2015 Paris Agreement reached an international consensus to address climate change by strengthening emission reduction targets to keep global temperature rise well below $2.0^{\circ} \mathrm{C}$ and engaging into efforts to limit the increase to $1.5^{\circ} \mathrm{C}$ under a stronger system of transparency and accountability for measuring progress. The 'all countries' policy includes the support actions of non-party stakeholders, such as businesses, investors, states, provinces, cities, authorities at sub-national and local level, financial institutions, and civil societies, among others, to reduce the emissions and building resilient societies in the light of a sustainable future (UNFCCC 2015).

The agreement comprises twenty-nine articles, dealing with mitigation, adaptation, loss and damage, finance, technology development and transfer, capacity-building, and transparency of action, global stock-take and support. Accordingly, support for climate action to reduce emissions and building resilience in developing countries will continue to be provided by developed nations, although also other countries are persuaded to offer or continue the provision of such support on a voluntarily basis. Likewise, from a local or national scale, all signing Parties have a legally binding obligation to prepare, communicate and contribute to 
Table 1 Disaster risk reduction identified as cross-cutting issues in 10 of the 17 SDGs (adapted from UNISDR 2015c)

\section{Sustainable development goals related to disaster risk reduction}

G1. End poverty in all its forms everywhere

G2. End hunger, achieve food security and improved nutrition and promote sustainable agriculture

G3. Ensure healthy lives and promote well-being for all at all ages

G4. Ensure inclusive and equitable quality education and promote lifelong learning opportunities for all

G6. Ensure availability and sustainable management of water and sanitation for all

G9. Build resilient infrastructure, promote inclusive and sustainable Industrialization and foster innovation

G11. Make cities and human settlements inclusive, safe, resilient and sustainable

G13. Take urgent action to combat climate change and its impacts

G14. Conserve and sustainably use the oceans, seas and marine resources for sustainable development

G15. Protect, restore and promote sustainable use of terrestrial ecosystems, sustainably manage forests, combat desertification, and halt and reverse land degradation and halt biodiversity loss
Target 1.5.-Building the resilience of the poor

Target 2.4.-Advancing actions in mainstreaming disaster risk reduction and climate adaptation into agriculture sector planning and investments in order to promote resilient livelihoods, food production and ecosystems

Target 3.d.- Strengthening early warning and risk reduction of national and global health risks (resilient health systems)

Target actions 4.7 and 4.a.-Building and upgrading education facilities and promoting education for sustainable development, contribute significantly to resilience-building in the education sector

Target 6.6.-Protecting and restoring water-related ecosystems, will significantly contribute to strengthening the resilience of communities to water-related hazards and mainstreaming ecosystem-based approaches

Targets 9.1 and 9.a.-Developing sustainable and resilient infrastructure development to protect existing and future infrastructure investments

Action targets 11.1, 11.3, 11.4, 11.5, 11.b and 11 . c.- -Upgrading urban slums, integrated urban planning, reducing social and economic impacts of disaster risk, building the resilience of the urban poor, adopting and implementing urban policies

Targets 13.1-13.3 and 13.a-13.b.- Strengthening the integration between disaster and climate resilience to protect broader development paths at all levels and influencing the provision of long-term financing for addressing disaster and climate risk, aiming at a transformative change

Target action 14.2.- Reducing disaster risk and increase in demand for healthy marine and coastal ecosystems

Target actions 15.1-15.4 and 15.9.-Contributing to resilience building by managing and restoring forests, combating land degradation and desertification, conserving mountain ecosystems and their biodiversity and integrating ecosystem and biodiversity values into national and local planning, development processes, poverty reduction strategies mitigation, but Parties are not legally bound at the international level to achieve their targets (UNFCCC 2015).

\section{Cross Cutting Themes and Issues Between Declarations}

In many respects it is possible to see evident linkages between climate change, disaster risk reduction and sustainable development as well as in the financing for development, that have been identified in the 2015 UN Landmark agreements. By its very nature, the interaction of weather-related and climate hazards with exposed and vulnerable individuals and communities around the globe should not be neglected. For example, from the year 2005 to 2014 , although this data is not complete, it was determined that approximately 700,000 people died, 1.7 billion inhabitants were affected, and economic losses mounted $\$ 1.4$ trillion in disasters worldwide (UNFAO 2015).

As cited by the Intergovernmental Panel on Climate Change (IPCC 2012), a changing climate modifies the frequency, intensity, spatial extent, duration, speed of onset and 
timing of weather related and climate hazards. Moreover, the diversity, complexity and severity of the impacts of both, extreme and non-extreme weather or climate events on vulnerability to future extreme events by influencing resilience, coping capacity, and adaptive capacity has been widely recognized (IPCC 2012). A further problem is that the severity of extreme events is strongly associated with the degree of vulnerability and exposure and will be a major driver for future temporary and permanent population displacement which, in addition to migration due to other causes, will also be a challenging issue for all governments in the years to come.

In the absence of equality and social wealth, coping and adaptive capacity at local and sub-national levels, lives and livelihoods are threatened and generating challenges for disaster risk management and adaptation.

\section{On the Missing Link Between Science and Technology, Policy Making and Practice}

\section{Preliminary Considerations}

Within the last few years there has been a growing interest in linking science and technology, policy-making, and practice for disaster risk reduction and management (UNISDR STAG 2013 and 2015 reports). This concern has been indirectly pointed out since the Rio Declaration in 1992, when the issue of the precautionary principle as an approach to disaster risk management was introduced. Accordingly, it was stated that 'in order to protect the environment, the precautionary approach shall be widely applied by States according to their capabilities. Where there are threats of serious or irreversible damage, lack of full scientific certainty shall not be used as a reason for postponing cost-effective measures to prevent environmental degradation' (Rio Declaration 1992).

The unification of science and policy making around practice is crucial for tailoring efficient and effective implementation strategies for DRR and DRM. Uhlenbrock et al. (2014) argue that scientists have a key role in informing public policy and science should serve as a foundation to the decision-making process. A central feature of this positioning indeed unveils a delicate situation since 'science is such a powerful and omnipresent way to frame policy questions. But, on the other hand, this very framing means that the way to attack an opponent's position is to attack the science' (Boehlert 2007).

The work by Kahneman (2011) suggests that the majority of decisions are taken fast, as a function of feelings, previous experiences, associations, habits, trivial consequences, or evident preferences. Along this line of thought, scientific knowledge should be influential in decision-making processes based on beliefs and values, so that a solid bond to decision making can be constructed (von Winterfeldt 2013).

The focus of science should not be restricted to provide 'the right information, at the right time, for the right people', but scientific research should also be 'useful, usable and used' (Boaz and Haydn 2002). Nonetheless, there is not a quick route to build a sound interface between science and technology, policy making and practice, unless integrated research into disaster risk is carried out (Alcántara-Ayala et al. 2015; Cutter et al. 2015).

\section{Integrated Research on Disaster Risk}

Integrated Research on Disaster Risk (IRDR) is a multi-disciplinary approach to strengthen capacity at global, regional and local levels to address hazards and generating scientific-based decisions on actions to reduce their impacts. Aiming at developing trans-disciplinary, multi-sectorial alliances for in-depth, practical disaster risk reduction research studies and the implementation of effective evidence-based disaster risk policies and practices, the Integrated Research on Disaster Risk program was set up under the umbrella of the International Council for Science (ICSU), the International Social Science Council (ISSC) and the United Nations Office for Disaster Risk Reduction (UNISDR). The main purposes of IRDR involve:

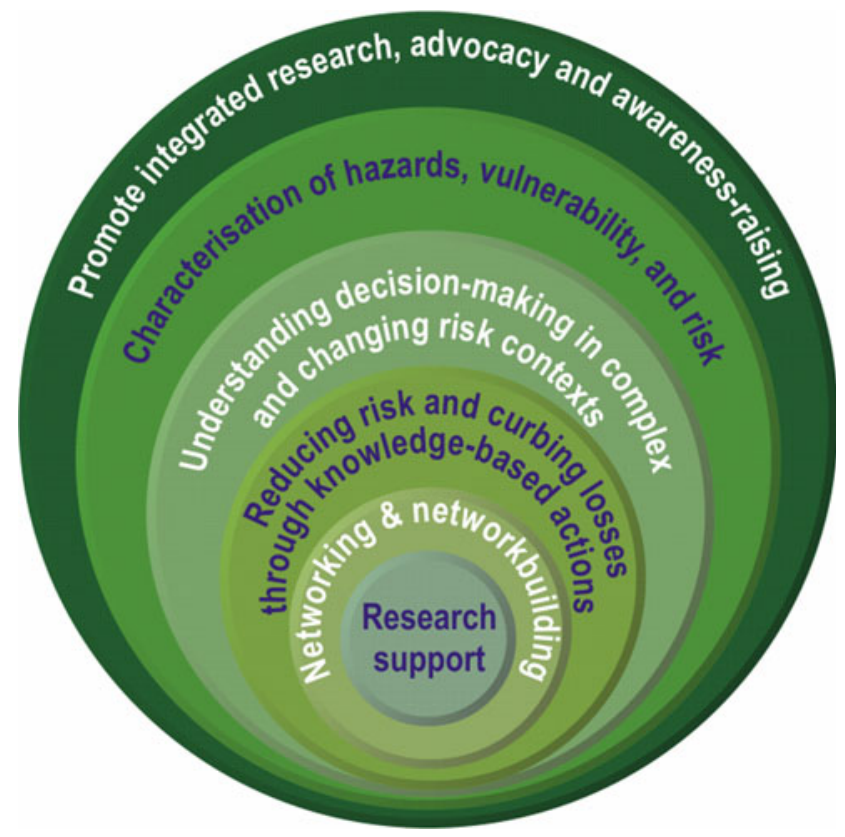

Fig. 4 Goals of the integrated research on disaster risk (IRDR) programme 
(a) "Characterizing hazards, vulnerability, and risk by identifying hazards and vulnerability leading to risks, and forecasting, assessing, and dynamic modeling";

(b) "Understanding decision-making in complex and changing risk contexts by identifying decision-making systems, their contexts, and their interactions, and improving the quality of decision-making practice"; and

(c) "Reducing risk and curbing losses through knowledge-based actions through vulnerability assessments, and the analysis of effective approaches to risk reduction" (IRDR 2013)

In order to summarise these purposes Fig. 4 provides a visual summary.

\section{Other Science and Technology Mechanisms for Implementation of the UN Frameworks for Informing Policy and Practice}

In seeking to advance the negotiations and discussions process of the post-2015 Framework for Disaster Risk Reduction, three major priority areas for action and scientific engagement in DRR and DRM were recognized by the UNISDR Scientific and Technical Advisory Group (STAG) and the Major Group on Science and Technology, in partnership with Regional and Global Platforms: (a) Sharing knowledge for action; (b) Using a multidisciplinary approach to research; and (c) Building systems resilience through local, national, regional and international partnerships (Aitsi-Selmi et al. 2015).

Concrete recommendations to be enhanced by STAG and IRDR - as the representative of the Major Group on Science and Technology - to build a partnership to support the integration of science in Disaster Risk Reduction (DRR) include:

1. Establishment of national DRR science-policy councils/platforms or national focal points for science to support disaster risk reduction and management;

2. Understanding the root causes and underlying risk factors of disaster risk (see Oliver-Smith et al. 2016);

3. Carrying out a periodic review of knowledge needs, new science, and research gaps;

4. Using the expanding science and technology evidence base to support capacity building and interdisciplinary capacity development for disaster risk management;

5. Leveraging science for DRR by promoting the dialogue between decision makers and researchers to guarantee integrated disaster risk governance;

6. Supporting integrated and holistic approaches to the use of science and technology for DRR;
7. Increasing the role of social science from a multidisciplinary approach to understand behavior and decision making in DRR and the role of the wider societal context in disaster risk creation and reduction;

8. Promoting open access, multi-hazard data platforms and standardized perspectives and tools for mapping and the use of data and scenarios that make science meaningful to decision-makers and people;

9. Using participatory approaches for communities to work together in the co-production of risk knowledge;

10. Investigating and documenting the effects of disasters and DRR interventions, including the ethical dimension of scientific research;

11. Strengthening DRR science-policy and cross-sectoral dialogues to facilitate risk assessments, post-disaster reviews, data sharing, and decision-making;

12. Developing guidelines for evidence-based risk assessments and their implementation to support the practical application of risk assessment (Aitsi-Selmi et al. 2016) (Fig. 5).

\section{Challenges for the Integration of Science into International Policy Development for Landslide Disaster Risk Reduction}

In spite of the uncertainty for predicting landslide occurrence in time and space, landslide risk assessments offer valuable insights in terms of hazard evaluation, vulnerability analysis, and elements at risk, which can be useful for simple tasks such as identifying symptoms of slope instability in the field, in addition to landslide mapping, instrumentation, monitoring and for designing and implementing Early Warning Articulated Systems (EWAS's). The main attribute of EWAS's is the inclusion of the human dimension of disaster risk as the core of the system. It involves a process aiming at the comprehensive understanding of disaster risk by the exposed communities by exploring the underlying or root causes of disasters. Likewise, hazard assessment, the analysis of risk perception, and the different multi-dimensions of vulnerability and resilience to apprehend and communicate risk are integrated into the warning system. In consequence, EWAS's intend to provide a mechanism of awareness, knowledge-sharing, preparedness and capacity building for people to understand disaster risk as a social construct and its potential consequences, so that assessment of likely disaster scenarios, realistic structural and non-structural measures, risk management procedures, and response strategies and actions, can be properly enhanced (Alcántara-Ayala and Oliver-Smith 2017).

Investigations concerning landslide hazards and their associated vulnerability have been dominated by 
Fig. 5 Recommendations for building the interface between science and technology for policy informing guidance (adapted from STAG and IRDR)

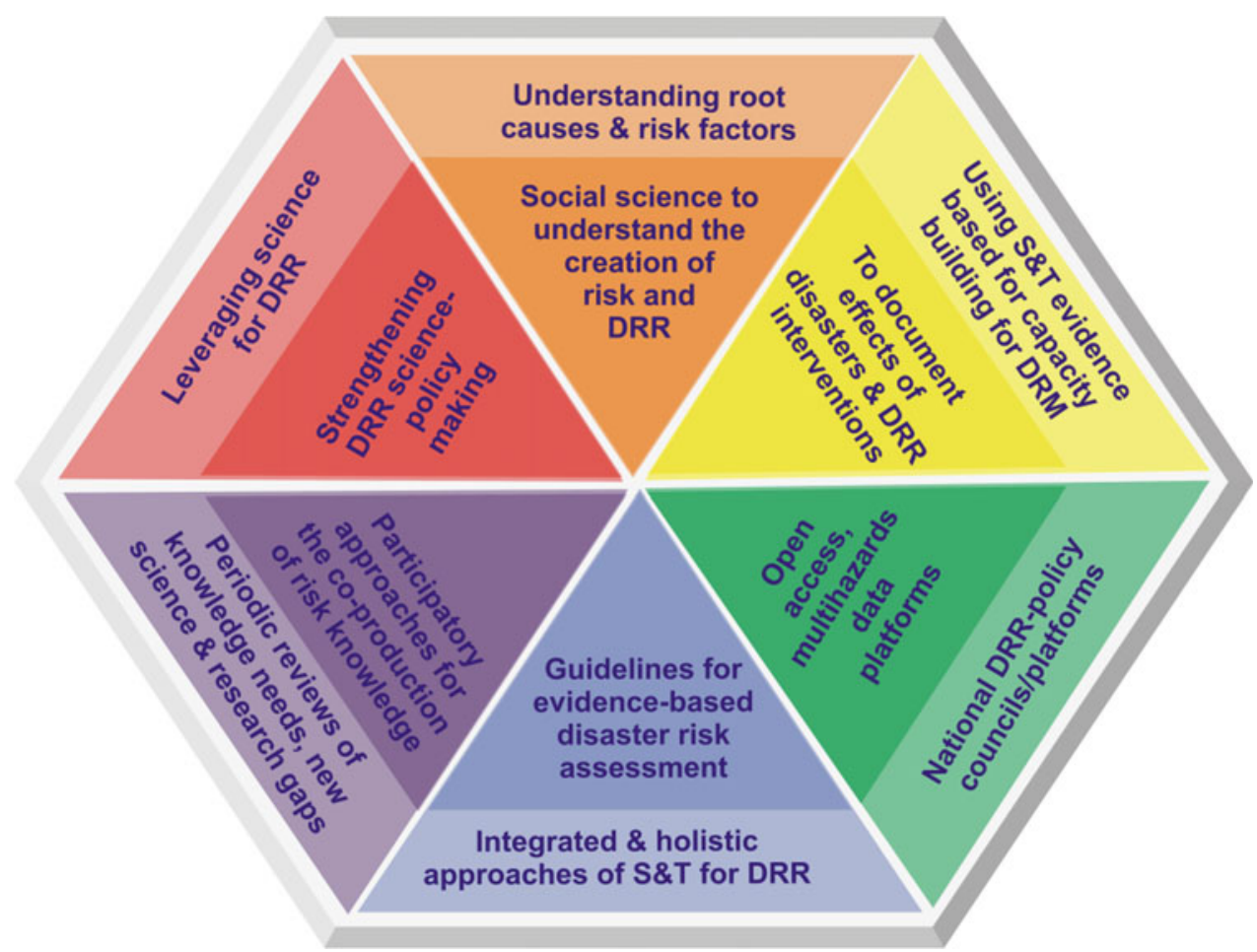

mono-disciplinary perspectives, although quite recently multi-disciplinary and interdisciplinary research have also contributed to the understanding of landslide disasters. As in the case of other hazards, the work and new direction of work on landslide disaster risk, requires the need to move towards integrated research with a transdisciplinary angle, so that different stakeholders can be fruitfully engaged in the co-production of disaster risk knowledge. To do so in the best possible way, a series of challenges must be faced in terms of the approach towards disaster risk per se, and the impasse scenarios generated by the nature of policy making and practice, as follows:

\section{(a) Landslide disaster risk approach}

(1) Understanding disaster risk as a social construct derived from the interaction between societies and the environment to build territories based on models of development that have been derived in the creation of vulnerability and exposure conditions to hazards (Blaikie et al. 1994; Wisner et al. 2004; Burton 2010, 2015; Oliver-Smith 2013; Oliver-Smith et al. 2016). Along the same line, the use of the term natural disasters should be avoided (Briceño 2015).

(2) Identifying and addressing the root or underlying causes of disaster risk and disasters (Blaikie et al. 1994; Wisner et al. 2004; Burton 2010, 2015; Oliver-Smith 2013; Oliver-Smith et al. 2016).
(3) Recognizing and dealing with dynamic pressures or drivers of disaster risk, as they favor vulnerability and exposure and intensify unsafe conditions (Blaikie et al. 1994; Wisner et al. 2004; Burton 2010, 2015; Oliver-Smith 2013; Oliver-Smith et al. 2016). In the case of landslides, particular attention must be given to those aspects known as or associated with anthropogenic determining factors of hillslope instability (i.e., population growth and spread into areas with unstable slopes, the rural-urban interface, and urbanization processes, deforestation processes, mining, excavations, deficient drainage and sewage systems, land degradation, land-use changes, etc.).

(4) Anticipating low-frequency, high magnitude landslide events to try to provide the best possible reliable estimates, and preventing high-frequency, low magnitude landslides by addressing root causes and drivers of risk.

(5) Enhancing the availability of consistent landslide hazard, vulnerability and exposure data, and filling the gaps of landslide knowledge.

(6) Stimulating landslide community-based strategies and applying landslide risk reduction measures to those communities predicted to be at risk in the future (Anderson et al. 2014).

(7) Design and implementation of Early Warning Articulated Systems (EWAS's) as integrated 
mechanisms for understanding the social construction of disaster risk through awareness, knowledge-sharing, preparedness and capacity building in terms of hazard, vulnerability and exposure (Alcántara-Ayala and Oliver-Smith 2017).

(b) Scientist, policy makers and practice

(8) Definition of policy issues as scientific questions has to be carefully achieved by scientists and policy makers (Boehlert 2007).

(9) Reconciling the supply of, and demand for, scientific information in order to produce information that is needed and used by decision makers ( $\mathrm{McNie}$ 2007).

(10) When communicating science, enough evidence and support should be provided without overwhelming the policy makers and practitioners with technical details (Uhlenbrock et al. 2014).

(11) Characterizing risk uncertainties and their associated implications for policy makers.

(12) Fostering the understanding and communication of uncertainties, in addition to face-to-face continuous interaction.

(13) Strengthening the relationships, trust and information flows necessary for full integration of scientific knowledge into the decision-making process (Jacobs 2002).

(14) Prioritizing livelihoods and well-being over economic interests and balancing public and private interests.

(15) Aiming at the co-production of knowledge as an iterative process, research agendas should be flexible to meet the needs of decision-makers (Lemos and Morehouse 2005).

(16) Expanding the role of chief scientific advisers and advisory boards at national, sub-national and desirably local levels (UNISDR 2015b; Cutter et al. 2015).

\section{Considerations for a Way Forward}

The impacts of landslides are just one example of the need for an all-hazard approach to disaster risk reduction. Indeed, progress in addressing disaster risk reduction relies not only on the adoption but also on the parallel implementation of targets, goals and actions derived from the four international agendas. These agendas are related to financing development, sustainability, limiting global temperature increase, enhancing adaptive capacity, strengthening resilience and reducing vulnerability to climate change and disaster risk, and avoiding the creation of future risks, that are considered to be key to reducing future harm.

This collective action can be portrayed as an 'open door' towards transformation and transformational strategies. The former involves 'fundamental changes in the attributes of a system, including value systems; regulatory, legislative, or bureaucratic regimes; financial institutions; and technological or biophysical systems' (O'Brien et al. 2012), whereas the latter, is focused on addressing risk derived from social structures and social behavior, including disaster risk management, development goals, policy, and practice (Nelson et al. 2007; O’Brien et al. 2012).

Despite the advance of science and technology in disaster risk, progress has been relatively limited in the many of the policy arenas. The notion of disaster risk reduction clearly includes a number of dimensions related to sustainable development, availability and mobilization of financing resources, and climate change adaptation that rely on the incorporation of multi-stakeholders at local, sub-national, national and global scales.

As noted in the IPPC "Managing the Risks of Extreme Events and Disasters to Advance Climate Change Adaptation" report (IPCC 2012), integration of disaster risk reduction and management and climate change adaptation with the international development agenda could lead to enormous benefit to policies and practices, at local, sub-national, national, regional and global scales.

The concept of science and technology and the link to develop an evidence base for policy is a complex one, and a promise to engage in a continued communication process towards specific commitments and targets is difficult when economic interests tend to override the sustainable use of the environment.

Regardless of the commitments made by authorities at member state level, the weighty work falls on the shoulders of local authorities, given that only DRR implementation at local scale can lead to desired regional and global deep-seated transformations.

With the confluence of the international initiatives, these historic milestones for the societies of tomorrow require a permanent dialogue among all stakeholders and a solid but transparent atmosphere of partnerships where commitment, responsibility and ethical values are top priority for implementing the 2015 UN Frameworks.

Acknowledgements For Irasema Alcántara-Ayala to lead on this work, thanks are due to CONACyT for the financial support kindly provided through the research project 156242 . 


\section{References}

AAAA (2015) Addis Ababa Action Agenda of the third international conference on financing for development (Addis Ababa Action Agenda), United Nations, New York. Available at http://www.un. org/esa/ffd/wp-content/uploads/2015/08/AAAA_Outcome.pdf

Aitsi-Selmi A, Blanchard K, Al-Khudhairy D, Ammann W, Basabe P, Johnston D, Ogallo L, Onishi T, Renn O, Revi A, Roth C, Peijun S, Schneider J, Wenger D, Murray V (2015) UNISDR STAG 2015 report: science is used for disaster risk reduction. Available at http:// preventionweb.net/go/42848

Aitsi-Selmi A, Murray V, Wannous C, Dickinson C, Johnston D, Kawasaki A, Stevance AS, Yeung T, et al (2016) Reflections on a science and technology agenda for 21 st century disaster risk reduction. Based on the scientific content of the 2016 UNISDR science and technology conference on the implementation of the Sendai framework for disaster risk reduction 2015-2030. Int J Dis Risk Sci 7(1):1-29. doi:10.1007/s13753-016-0081-x

Alcántara-Ayala I (2016) On the multi-dimensions of integrated research on landslide disaster risk, In: Aversa S, Cascini L, Picarelli L, and Scavia C (eds) Landslides and engineered slopes. Experience, theory and practice, proceedings of the 12th international symposium on landslides (Napoli, Italy, 12-19 June 2016). CRC Press

Alcántara-Ayala I, Oliver-Smith A (2017) The necessity of early warning articulated systems (EWASs): critical issues beyond response. In: Sudmeier-Rieux K, Fernandez M, Penna I, Jaboyedoff M, Gaillard JC (eds) Linking sustainable development, disaster risk reduction, climate change adaptation and migration. Springer (in press)

Alcántara-Ayala I, Altan O, Baker D, Briceño S, Cutter S, Gupta H, Holloway A, Ismail-Zadeh A, Jiménez Díaz V, Johnston D, McBean G, Ogawa Y, Paton D, Porio E, Silbereisen R, Takeuchi K, Valsecchi G, Vogel C, Wu G, Zhai P (2015) Disaster risks research and assessment to promote risk reduction and management. In: Ismail-Zadeh A, Cutter S (eds) Ad Hoc group on disaster risk assessment (ICSU-ISSC), Paris. Available from: http://www.icsu.org/science-for-policy/disasterrisk/documents/ DRRsynthesisPaper_2015.pdf (online)

Anderson M, Holcombe E, Holm-Nielsen N, Della Monica R (2014) What Are the emerging challenges for community-based landslide risk reduction in developing countries? Nat Hazards Rev, pp 128139. doi:10.1061/(ASCE)NH.1527-6996.0000125

Blaikie P, Cannon T, Davis I, Wisner B (1994) At risk: natural hazards, people's vulnerability and disasters. Routledge, New York

Boaz A, Hayden C (2002) Pro-active evaluators: enabling research to be useful, Usable and Used. Evaluation 8(4):44053

Boehlert SL (2007) The role of scientists in policymaking. AAAS-CSPA S\&T policy review: highlights from the 2007 forum on S\&T policy

Briceño S (2015) Looking back and beyond Sendai: 25 years of international policy experience on disaster risk reduction. Int $\mathrm{J}$ Disaster Risk Sci 6(1):1-7

Burton I (2010) Forensic disaster investigations in depth: a new case study model. Environ Sci Policy Sustain Dev 52(5):36-41

Burton I (2015) The forensic investigation of root causes and the post-2015 framework for disaster risk reduction. Int J Disaster Risk Reduct 12:1-2

Cutter SL, Ismail-Zadeh A, Alcántara-Ayala I, Altan O, Baker DN, Briceño S, Gupta H, Holloway A, Johnston D, McBean GA, Ogawa Y, Paton D, Porio E, Silbereisen RK, Takeuchi K, Valsecchi GB, Vogel C, Wu G (2015) Global risks: pool knowledge to stem losses from disasters. Nature 522:277-279
Dilley M, Chen RS, Deichmann W, Lerner-Lam AL, Arnold M (2005) Natural disaster hotspots: a global risk analysis. The World Bank, Washington

ICSU_LAC (2010) Science for a better life: developing regional scientific programs in priority areas for Latin America and the Caribbean. In: Cardona OD, Bertoni JC, Gibbs T, Hermelin M, Lavell A (eds) Understanding and managing risk associated with natural hazards: an integrated scientific approach in Latin America and the Caribbean, vol 2. ICSU-LAC/CONACYT, Rio de Janeiro and Mexico City, $88 \mathrm{pp}$

IPCC (2012) Summary for policymakers. In: Field CB, Barros V, Stocker TF, Qin D, Dokken DJ, Ebi KL, Mastrandrea MD, Mach KJ, Plattner GK, Allen SK, Tignor M, Midgley PM (eds) Managing the risks of extreme events and disasters to advance climate change adaptation. A special report of working groups I and II of the intergovernmental panel on climate change. Cambridge University Press, Cambridge, UK, and New York, NY, USA, pp 3-21

IRDR (2013) Integrated research on disaster risk strategic plan 20132017, Beijing, China. http://www.irdrinternational.org/wp-content/ uploads/2013/04/IRDR-Strategic-Plan-2013-2017.pdf

Jacobs K (2002) Connecting science, policy, and decision making: a handbook for researchers and science agencies. National Oceanic and Atmospheric Administration, Office of Global Programs

Kahneman D (2011) Thinking, fast and slow (Ferrar, Straus, and Giroux, New York)

Kennedy I T R, Petley D N, Williams R, Murray V (2015) A systematic review of the health impacts of mass earth movements (landslides). In: PLOS currents disasters, 1 ed

Lavell A (1996) Degradación Ambiental, Riesgo y Desastre Urbano: Problemas y Conceptos. In: Fernández MA Ciudades en Riesgo. Lima, Perú: LA RED. USAID

Lavell A (2003a) Sobre la Gestión del Riesgo: Apuntes hacia una Definición. Available from: http://disaster-info.net/cepredenac/pdf/ pnud/productos/Documentos/definicion.pdf (online)

Lavell A (2003b) La gestión local del riesgo, nociones y precisiones en torno al concepto y la práctica. CEPREDENAC-PNUD

Lemos MC, Morehouse B (2005) The co-production of science and policy in integrated climate assessments. Glob Environ Change 15:57-68

McNie EC (2007) Reconciling the supply of scientific information with user demands: an analysis of the problem and review of the literature. Environ Sci Policy 10:17-38

Nelson DR, Adger N, Brown K (2007) Adaptation to environmental change: contributions of a resilience framework. Ann Rev Environ Resour 32:395-419

O’Brien K, Pelling M, Patwardhan A, Hallegatte S, Maskrey A, Oki T, Oswald-Spring U, Wilbanks T, Yanda PZ (2012) Toward a sustainable and resilient future. In: Field $\mathrm{CB}$, Barros V, Stocker TF, Qin D, Dokken DJ, Ebi KL, Mastrandrea MD, Mach KJ, Plattner GK, Allen SK, Tignor M, Midgley PM (eds) Managing the risks of extreme events and disasters to advance climate change adaptation. managing the risks of extreme events and disasters to advance climate change adaptation. A special report of working groups I and II of the intergovernmental panel on climate change. Cambridge University Press, Cambridge, UK, and New York, NY, USA, pp 437-486

Oliver-Smith A (2013) A matter of choice. Int J Disaster Risk Reduct 3 (1): $1-3$

Oliver-Smith A, Alcántara-Ayala I, Burton I, Lavell A (2016) Forensic investigations of disasters (FORIN): a conceptual framework and guide to research. IRDR FORIN Publication No. 2. Integrated Research on Disaster Risk, ICSU, Beijing, 56 pp

Petley DN (2012) Landslides and engineered slopes: protecting society through improved understanding. In: Eberhardt E, Froese C, 
Turner K, Leroueil S (eds) Landslides and engineered slopes. CRC Press, Canada

Rio Declaration (1992) Report on the UN conference on environment and development, Rio de Janeiro, 13-14 June 1992, UN doc. A/CONF.151/26/Rev.1 (vols 1-III)

Uhlenbrock K, Landau E, Hankin E (2014) Science communication and the role of scientists in the policy discussion. In: Drake JL, Kontar YY, Rife GS (eds) New trends in earth-science outreach and engagement advances in natural and technological hazards research, vol 38. Springer, Enfield, pp 93-105

UNFAO (2015) (http://www.fao.org/3/a-i5128e.pdf)

UNFCCC (2015) Adoption of the Paris agreement, COP 21, Paris, France. Available at: https://unfccc.int/resource/docs/2015/cop21/ eng/109r01.pdf

UNISDR (2009) Terminology on disaster risk reduction. Available from: http://www.unisdr.org/files/7817_UNISDRTerminology English.pdf (online)
UNISDR (2015a) Sendai framework for disaster risk reduction 20152030, Geneva, Switzerland

UNISDR (2015b) Proposed updated terminology on disaster risk reduction: a technical review, background paper. The United Nations Office for Disaster Risk Reduction. Geneva, Switzerland. Available from: http://www.preventionweb.net/files/45462 backgoundpaperonterminologyaugust20.pdf (online)

UNISDR (2015c) Disaster Risk reduction and resilience in the 2030 agenda for sustainable development, Geneva, Switzerland

United Nations (2015) Transforming our world: the 2030 agenda for sustainable development, A/RES/70/1

von Winterfeldt D (2013) Bridging the gap between science and decision making. Proc Natl Acad Sci U S A 110(S3):14055-14061

Wisner B, Blaikie P, Cannon T, Davis I (2004) At risk: natural hazards, people's vulnerability and disasters (2nd ed). New York: Routledge
Open Access This chapter is licensed under the terms of the Creative Commons Attribution 4.0 International License (http:// creativecommons.org/licenses/by/4.0/), which permits use, sharing, adaptation, distribution and reproduction in any medium or format, as long as you give appropriate credit to the original author(s) and the source, provide a link to the Creative Commons license and indicate if changes were made.
The images or other third party material in this chapter are included in the chapter's Creative Commons license, unless indicated otherwise in a credit line to the material. If material is not included in the chapter's Creative Commons license and your intended use is not permitted by statutory regulation or exceeds the permitted use, you will need to obtain permission directly from the copyright holder. 